\title{
FUZZY PROGNOSIS SYSTEM FOR DECISION MAKING TO VIBRATIONS MONITORING IN GAS TURBINE
}

\author{
SAADAT Boulanouar ${ }^{1 *}$, HAFAIFA Ahmed $^{1,2}$, BELHADEF Rachid $^{3}$, KOUZOU Abdellah $^{1,2}$ \\ ${ }^{1}$ Applied Automation and Industrial Diagnostics Laboratory, Faculty of Science and Technology, \\ University of Djelfa 17000 DZ, Algeria, e-mail: B.saadat@univ-djelfa.dz, \\ ${ }^{2}$ Gas Turbine Joint Research Team, University of Djelfa, Djelfa 17000 DZ, \\ Algeria,e-mail: a.hafaifa@univ-djelfa.dz, kouzouabdellah@ieee.org \\ ${ }^{3}$ Faculty of Science and Technology, University of Sedik Ben yahia of Jijel, \\ Algeria, e-mail: r.belhadef@univ-jijel.dz
}

\begin{abstract}
This paper proposes a decision making approach based on the development of a fuzzy prognostic system to ensure the vibrations monitoring of a gas turbine based on real time information obtained from different installed sensors. In this approach the case of incomplete obtained data which may occur frequently is taken into account by using an approach of full data reconstitution form incomplete data. The proposed fuzzy prognostic system approach presented in this paper allows the analysis of the data obtained via the vibration indicators of a gas turbine system for the accurate identification of the faults to avoid the performance degradation of such systems. In order to prove the robustness of the proposed approach presented in this paper, several tested has been performed.
\end{abstract}

KEYWORDS: Prognosis system, fuzzy system, fuzzy modeling, fuzzy decision making, incomplete data, vibration in gas turbine

\section{Introduction}

Today the industrial maintenance sector has become increasingly computerized due to the integration of new technologies equipments such as the digital control and acquisition systems and measurement data tools. Indeed, a significant collection of data can be obtained which allows to give relevant information about the industrial systems and equipment, whereas, this information will be used effectively for the analysis and the monitoring of this industrial equipment. It is well obvious that these data are used to predict future decisions affecting the operation state of such equipment. On the other side, the obtained data should be reliable, which means that the collection of this data requires precise techniques that allow the treatment and the quality improvement of the obtained data. It is important to clarify that the actual data processing used in many industrial applications is still having some problems for real time applications. Because very often the treatment of this data are obtained in the presence of observations that their descriptive variables values are not all known. This is due to many reasons such as: reading errors, huge data collected from the sensor, false or duplicate data, false alarm (fugitive defects) and other reasons affecting the data assessment phase.

In industrial literature, several themes related to the treatment of vibration problems and to methods of studying fatigue and dynamic behavior of mechanical systems have been developed, to improve their analyzes and to find profitable solutions for these problems. Such as; Milan Žmindák in [14] proposed an approach of dynamic sensitivity analysis of general non-conservative asymmetric mechanical systems, for damping systems with applications to 
show the efficiency of this method of calculating derivatives of values and eigenvectors of this system. This can be applied for other uses of behavioral modeling of dynamical systems. Also, Robert Owsiński et al. in [23] have proposed a method for the identification of fatigue cracks using changes in system dynamics measurements, in order to obtain robust and reliable experimental results, using dynamic excitation generated by the force of inertia with an original method to identify damage based on image analysis of the fatigue fractures obtained.

Furthermore, Nadji Hadroug et al. in [18] have implemented a fuzzy diagnostic method for the detection of vibratory faults in gas turbines and Okipnyi Igor et al. in [20] have studied the reliability-based durability of a gas pipeline system to determine the fatigue resistance parameters, as part of the development of degradation indices of this system. Also, Tůma Jiří et al. in [28] have carried out an all-pass filters in active vibration control systems of weakly damped mechanical structures, to damp vibrations and Mohamed Benrahmoune et al. in [16] have proposed an approach for detecting and modeling the vibratory behavior of a gas turbine, using the concept of neural networks, for the development of detection indices for defects caused by vibrations, to ensure stable operation and sure about this rotating machine.

However, several solutions have been proposed in several previous works to overcome these incomplete data processing problems and their use in real time [1, 5, 7-13, 19-21, 36]. The proposed work in this paper presents a contribution to this important industrial subject applied to a very vital important and complex industrial system which is the gas turbine. this proposed approach is based on an incorporated prognostic tools to ensure a robust maintenance strategy for the studied gas turbine. In fact, the diagnostic unit exploits the historical databases of an operating gas turbine for detecting and locating defects in this machine. Therefore, it possible to develop a prognosis faults tolerant method for the detection and the determination of a defect severity on the right location to ensure the monitoring strategy which fulfils the requirement of these types of systems. The complexity and the dynamic behaviour of gas turbine system increase the difficulty in obtaining a precise degradation model and in the same time the necessary time to have full data for ensuring the fast feedback within the right time.

In this paper a prognosis approach guided by these data in real time is proposed, it is based on the integration of the artificial intelligence tools using fuzzy logic. where the main aim is to ensure the supervision of gas turbines, this prognosis approach has the advantage that it does not require the use of the analytical models to predict the equipment degradation progress and to make the gas turbine performance monitoring improved. This method of fuzzy prognosis proposed in this paper permits to obtain information on system status based on the obtained gas turbine data, which will be useful for real time supervision. It is obvious that the use of the fuzzy logic has the advantage of expressing the data belonging to several classes of data allowing to better understand the system real situation and to predict the eventual changes towards fault conditions. However, their performances are strongly related to functional states during the implementation of this prognosis strategy.

\section{Prognosis system Introduction}

The need to improve the capacity of a diagnostic system in industrial processes requires industrial operators to use predictive approaches in real time, to quickly detect potential defects, even before their appearances. Thus, the planning of diagnostic actions accurately is required before these defects becomes serious and can significantly degrade the system security and disrupts the production and its quality [2, 4, 6, 17, 22, 26-29, 33]. For this purpose, this work proposes the use of a fault prognosis system applied to the detection of faults and its degree in gas turbine based on vibrations measurement. where the main aim is to automatically improve the performance of the operating states of this industrial process 
studied in this work. Indeed, the advantage of using these prognostic approaches allows the better management of information on the state of industrial equipment, and to provide accurate information on the current status provided by diagnostic systems, and the expected future state provided by the diagnostic systems, of each component of the equipment. Using data from the system to be monitored and equipment inspection data, to establish probable future behavior situations.

This, increase maintain factors in good operational condition of the industrial systems for deciding on operating state on real-time with low cost. The prognosis system addresses these problems in order to estimate as accurately as possible the remaining life of the system $[3,25$, 30-32, 34, 35-36]. Indeed, the knowledge necessary a priori on a prognosis system is function of cause / effect, as shown in Figure 1, that are leading to degradation and their influences on the appearance of the industrial system failures itself.

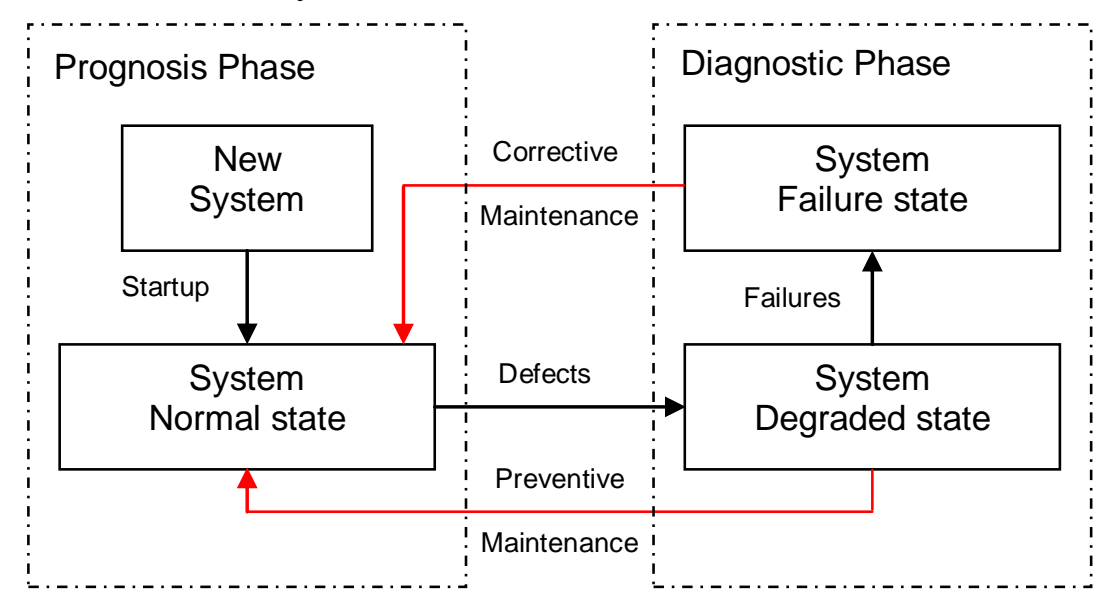

Fig. 1 Relationship of cause / effect relationship between prognostic system and diagnostic system

In this work a fuzzy logic techniques prognostic approach is proposed for modelling better the degradation of the gas turbine system to increase their safety security. To achieve this task, the construction of a database is required to predict the future decisions affecting the operating state of the industrial equipment. Once the data is collected on the studied system, the treatment will be carried out using the concept of fuzzy logic, in order to extract performance indicators reviewed for the gas turbine. Indeed, the majority of industrial systems are complex and the collection of data is difficult to collected because of their nonlinearity, their parameter variation, and due to their quality of measurable variables. The fuzzy logic offers major advantages in such situations, when no precise mathematical model of the process or when it has strong inaccuracies in the measured data [15, 24, 30].

A fuzzy inference system is proposed in this work, offering good performance face of the complex examined gas turbine system data classification. In addition, they support the addition of new classes and can easily be trained incrementally in real time. A fuzzy inference system of order one consists of a set of fuzzy rules of the following form:

$$
\text { Rule }^{(i)}: \text { IF } \psi \in C^{(i)} \text { Then: } \hat{y}^{(i)}=\left(G_{1}^{(i)}(\psi) ; \ldots ; G_{c}{ }^{(i)}(\psi)\right)
$$

Where ${ }^{\psi}$ is the vector of the entries weighted by the degrees of activation of the rules, $G_{c}{ }^{(i)}$ is the linear consequence function and $\hat{y}^{(i)} \in \mathfrak{R}^{c}$ is the vector of belonging to the $c$ different classes.

The premises of rules are defined by the fuzzy membership of prototypes $C^{(i)}$ of clusters in the input space - which are characterized by a center $\mu(i)$ and a covariance matrix $\sum^{(i)}$. The 
degree of fuzzy membership $w^{(i)}(\psi)$ is calculated by a hyper-ellipsoidal radial function, as a function of the distance $d_{\Sigma^{(i)}}\left(\psi, \mu^{(i)}\right)$ between $\psi$ and $C^{(i)}$, given by:

$$
w^{(i)}(\psi)=\frac{1}{1+d_{\Sigma^{(i)}}\left(\psi, \mu^{(i)}\right)}
$$

The conclusions of the rules give the fuzzy belonging to the different classes, and for the SIF of order one, these degrees of membership are obtained by linear functions of the entries:

$$
\hat{y}^{(i)}=\left(G_{1}{ }^{(i)}(\psi) ; \ldots ; G_{c}{ }^{(i)}(\psi)\right)
$$

Hence the linear consequence function $G_{k}{ }^{(i)}(\psi)$ of the rule $i$ for the class $k$ is given by:

$$
G_{k}^{(i)}(\psi)=\theta_{k}^{(i) T} \psi=\theta_{k .1}{ }^{(i) T} \psi_{1}+\ldots+\theta_{k . n}{ }^{(i) T} \psi_{n}
$$

With $\theta_{k}=\left[\pi_{1}, \pi_{2}, \ldots, \pi_{R}\right]$ is the vector which linear parameters, $\pi$ is vector of the parameters of $i$ th subset or rule and $T$ is the transpose of a vector.

The fuzzy sum-product inference is then used to calculate the system output for each class:

$$
\hat{y}(\psi)=\sum_{i=1}^{r} w^{(i)}(\psi) \cdot \hat{y}^{(i)}(\psi)
$$

where $r$ is the number of fuzzy rules.

The class of $\psi$ is chosen as the label corresponding to the maximum component of the output of $\hat{y}^{(i)}=\left(\hat{y}_{1}(\psi) ; \ldots ; \hat{y}_{c}(\psi)\right)$, given by:

$$
\text { Cluster }(\psi)=\arg \max \hat{y}_{k}(\psi) \text { and } k=1, \ldots, c
$$

The data is collected continuously, some of the new data received reinforce and confirm the information contained in the previous data. Other data, however, provide new information, which may indicate a change in the conditions of use of the equipment or mean a change in the dynamics of the process.

As a result, it is necessary to adapt the structure of the predictive model accordingly: new information can lead to the construction of a new rule or the modification of an existing one. This adaptation process makes it possible to update according to each new available learning data, and recursively recalculate the covariance matrices as shown in the following Figure 2.

The problem of incremental consequence learning in a first-order fuzzy inference system can be solved by the Recursive Least Squares (RLS) method weighted by rule activations. If the $\Phi^{(i)}$ is the matrix of all the parameters of the linear consequences of the rule $i$, given by:

$$
\Phi^{(i)}=\left(\begin{array}{ccc}
\theta_{1,1}^{(i)} & \cdots & \theta_{1, c}^{(i)} \\
\vdots & \ddots & \vdots \\
\theta_{n, 1}^{(i)} & \cdots & \theta_{n, c}^{(i)}
\end{array}\right)
$$

where $\mathrm{c}$ is the number of classes and $\mathrm{n}$ is the size of the characteristic vector.

The matrix of the linear consequences can be recursively learned and given by:

$$
\Phi_{t}^{(i)}=\Phi_{t-1}^{(i)}+P_{t}^{(i)} \psi_{t} w^{(i)}\left(\psi_{t}\right)\left(y_{t}-\psi_{t}^{T} \Phi_{t-1}^{(i)}\right), \quad t=2,3,4, \ldots
$$

Hence the covariance matrices $P^{(i)}=\left(\sum_{k=1}^{t} \psi_{k} \cdot \psi_{k}^{T}\right)^{-1}$ are also updated recursively and given by: 


$$
P_{t}^{(i)}=P_{t-1}^{(i)}-\frac{P_{t-1}^{(i)} \psi_{t} \psi_{t}^{T} P_{t-1}^{(i)}}{\frac{1}{w^{(i)}\left(\psi_{t}\right)}+\psi_{t}^{T} P_{t-1}^{(i)} \psi_{t}}
$$

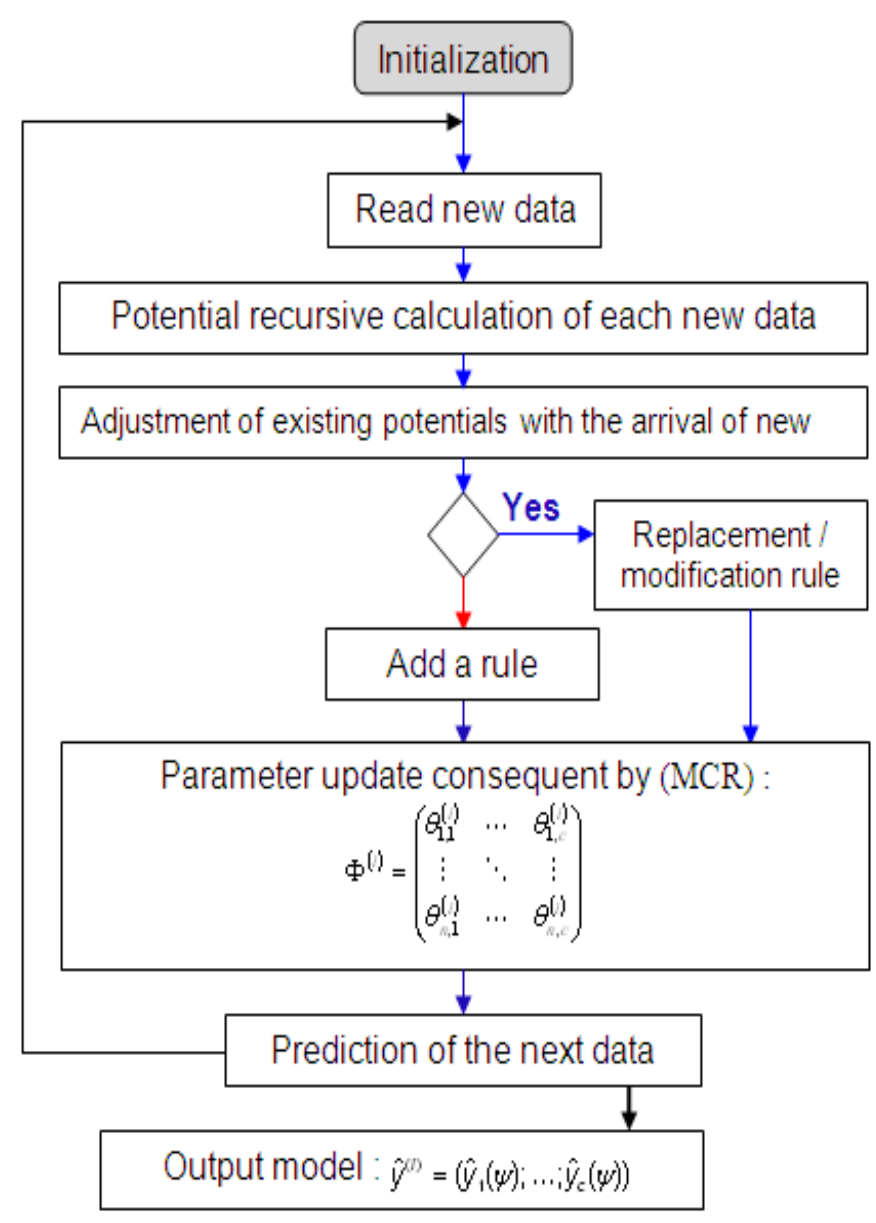

Fig. 2 Procedure of the learning algorithm

When a rule is generated, new linear parameters are added, parameters to be initialized. To take this into account, use the following formula:

$$
\left\{\begin{array}{l}
\hat{\pi}_{r+1}^{t}=\sum_{i=1}^{r} \lambda_{i} \hat{\pi}_{r+1}^{t-1} \\
\Phi_{t}=\left[\hat{\pi}_{1(t-1)}^{T}, \hat{\pi}_{2(t-1)}^{T}, \ldots, \hat{\pi}_{r(t-1)}^{T}, \hat{\pi}_{r+1(t)}^{T}\right]
\end{array}\right.
$$

where $\lambda$ is a standardized activation vector.

Then, the covariance matrix is adapted as follows:

$$
\left[\begin{array}{cccccc}
R \zeta_{11} & \ldots & R \zeta_{1 r(n+1)} & 0 & \ldots & 0 \\
\ldots & \ldots & \ldots & \ldots & \ldots & \ldots \\
R \zeta_{r(n+1) 1} & \ldots & R \zeta_{r(n+1) r(n+1)} & 0 & \ldots & 0 \\
0 & 0 & 0 & \Omega & \ldots & 0 \\
\ldots & \ldots & \ldots & \ldots & \ldots & \ldots \\
0 & 0 & 0 & 0 & 0 & \Omega
\end{array}\right]
$$


With $\zeta$ is the covariance matrix element, $r$ represents the number of fuzzy rules equal to $R=\frac{r^{2}+1}{r^{2}}$.

Note that if there is a modification of one of the rules or not in the structure the covariance matrix keeps the same dimension.

A classification action by fuzzy rules can be used to classify defects by areas of operation. This action is to decide which subset of a partition belongs to a given observation. Generally, the fuzzy rules are of the "IF... THEN" and can represent relationships between input variables and output variables of industrial system. This action is shown in Figure 3 of the proposed fuzzy prognosis approach.

If $\mathrm{E}_{1}$ is Small and $\mathrm{E}_{2}$ Average Then Cause $f_{1}$

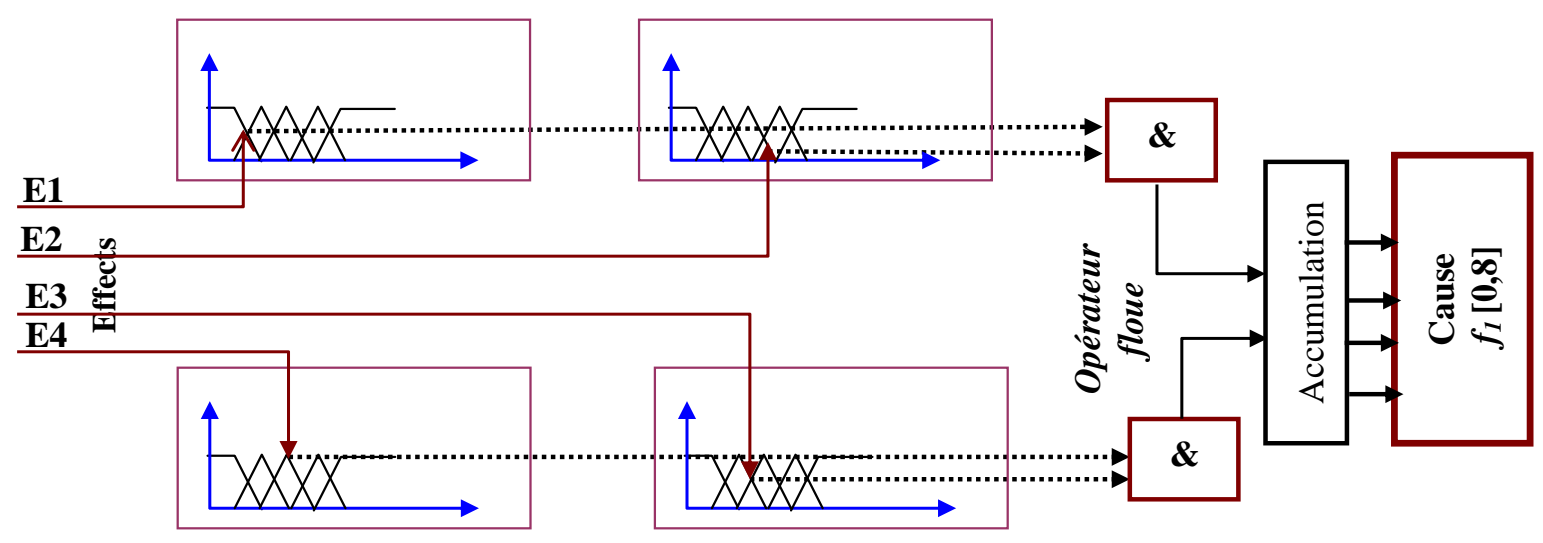

If $\mathrm{E}_{3}$ Average and $\mathrm{E}_{4}$ Small Then Cause $f_{l}$

Fig. 3 Fuzzy prognosis approach

The main advantages of this approach of fuzzy prognosis are their ability to adapt to failures to all type of defects in the gas turbine system with its flexibility to the dynamics parameters change of the gas turbine.

The main required prognostic parameter is the remaining time before failure (RUL) or the proximity of the date of failure according to the date of actual failure, the calculation of this factor represents a critical point in the prediction process; this parameter is set as follows:

$$
\text { Accuracy }=\frac{1}{N} \sum_{i=1}^{N} e^{\frac{D_{i}}{D_{0}}}
$$

With $D_{i}=\left|\hat{f}_{\text {fail }}(i)-t_{\text {fail }}(i)\right|$ is the distance between the expected failure instants, $D_{0}$ is a normalization constant whose value is based on the importance of the actual value in the application.

In the next section, the proposed method was tested for the identification of the degradation process of the gas turbine to identify the dominant modes of damage to this system. By a fuzzy inference system to determine the incomplete data of the system based on the fuzzy inputs issued from the fuzzification of the real inputs. Given a collection of rules, the inference mechanism is to derive a fuzzy set of outputs from the aggregation of the findings of all the fuzzy rules. 


\section{$3 \quad$ Applications and results}

In industrial reality, rotating machines are massively used in many industrial installations, where, the failures that can be encountered on these rotating machines are numerous, such as vibrations and unstable phenomena, so it is necessary to learn about their operating status, in order to be able to make the right decisions at the right time on their monitoring system. In this section, a fuzzy logic-based supervisory approach is adopted for the development of a prognostic system for vibration monitoring of an examined gas turbine. The studded machine is a gas turbine type GE MS 3002 gas, which is installed at the compressor station of Hassi R'Mel in southern Algeria, shown in Figure 4. The parameters directly affect the aging of this equipment are the operating temperature; Ambient temperature, the exhaust temperature $\left(T_{a m b}, T_{e x t}\right)$ and the vibrations.

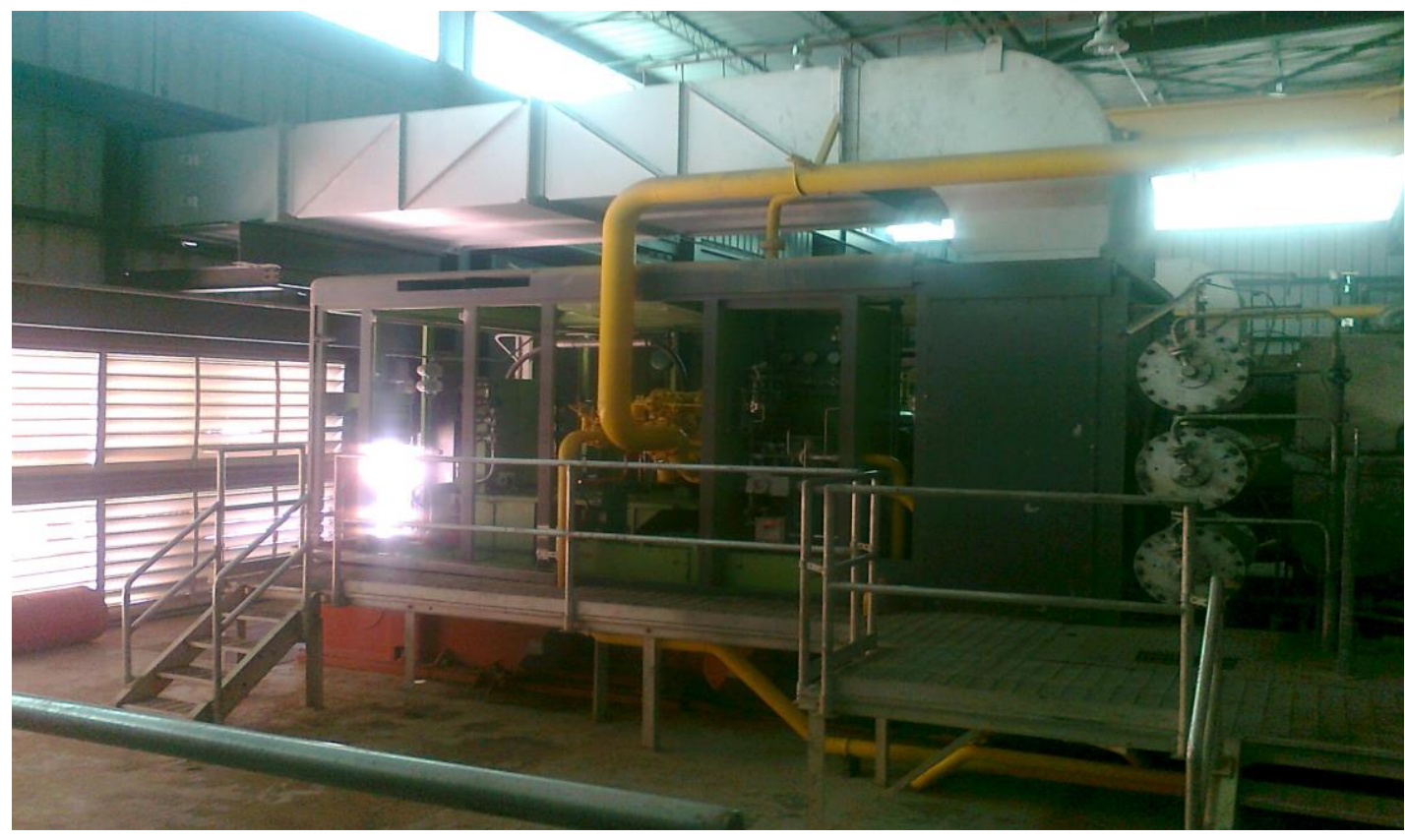

Fig. 4 Examined gas turbine MS 3002 GE

In practical way, in the case of the presence of a vibration excitation force caused by instabilities phenomena in the operation mode of the gas turbine, for example the case of the unbalance phenomena, the modeling procedure of this excitation force of the unbalance is defined as follows:

$$
F(t)\}=\left\{\begin{array}{c}
\sum m \cdot d \cdot \Omega^{2} \cdot \cos (\Omega t+\alpha) \\
\sum m \cdot d \cdot \Omega^{2} \cdot \sin (\Omega t+\alpha) \\
0 \\
0
\end{array}\right\}\left\{\begin{array}{l}
\text { Horizontal transition } \\
\text { Vertical transition } \\
\text { Vertical slope } \\
\text { Horizontal slope }
\end{array}\right.
$$

where $m . d\left(\mathrm{~kg} . \mathrm{m} / 10^{-6} \mathrm{~g} . \mathrm{mm}\right)$ represents the unbalance force, $m(\mathrm{~kg})$ is the rotor mass, $\alpha(\mathrm{m})$ is the eccentricity, $\Omega(\mathrm{red} / \mathrm{s})$ is the rotational speed and $\varphi(\mathrm{rad})$ is the unbalance wedge angle with respect to the angular reference of the turbine rotor.

This unbalance phenomenon modeling is shown in Figure 5, the unbalance phenomenon of the shafts is a cause of vibration quite common for gas turbines, because the vibration of the machine increases with the unbalance defect that causes fatigue of the machine components and therefore its instant failure. 


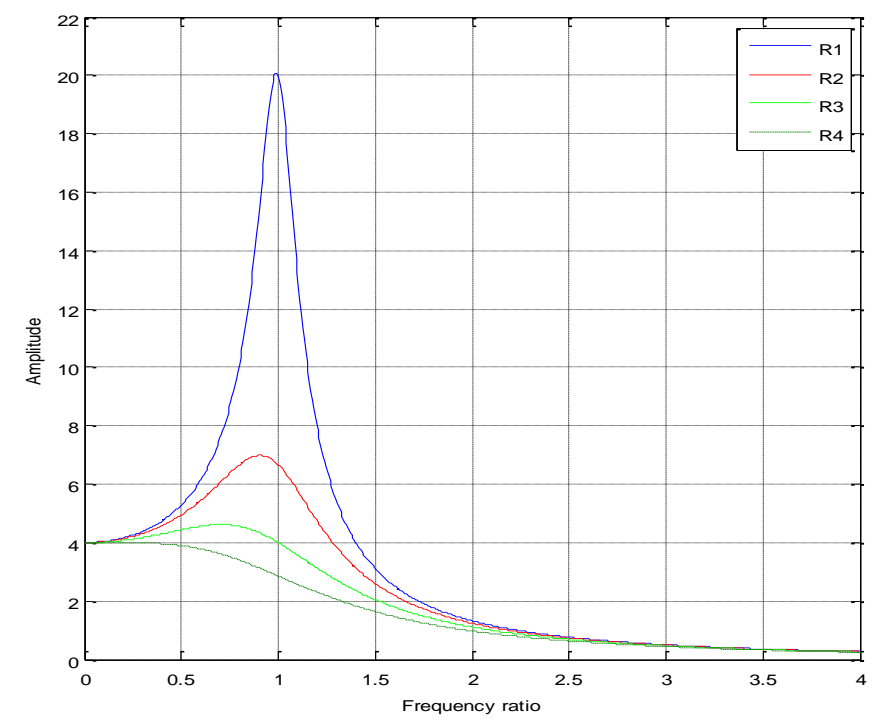

Fig. 5 Vibration response of a rotor subject to the unbalance phenomena

Data is collected over 24 hours by two recordings, shown in Figure 6; a recording has been done at night and the second was done in the morning on the GE 3002 operating turbine. Each record contains six ( three inputs and three output) variables; the outlet temperature of the exhaust gas, the ambient temperature intake area, the vibration of the bearings, when the temperature of the exhaust gases reach $427^{\circ} \mathrm{C}$ to $520^{\circ} \mathrm{C}$. These temperatures affect the operation and the life of the bearings, and this is often interpreted as vanes wear indicators of a turbine, this inevitably results in a phenomenon of vibrations.
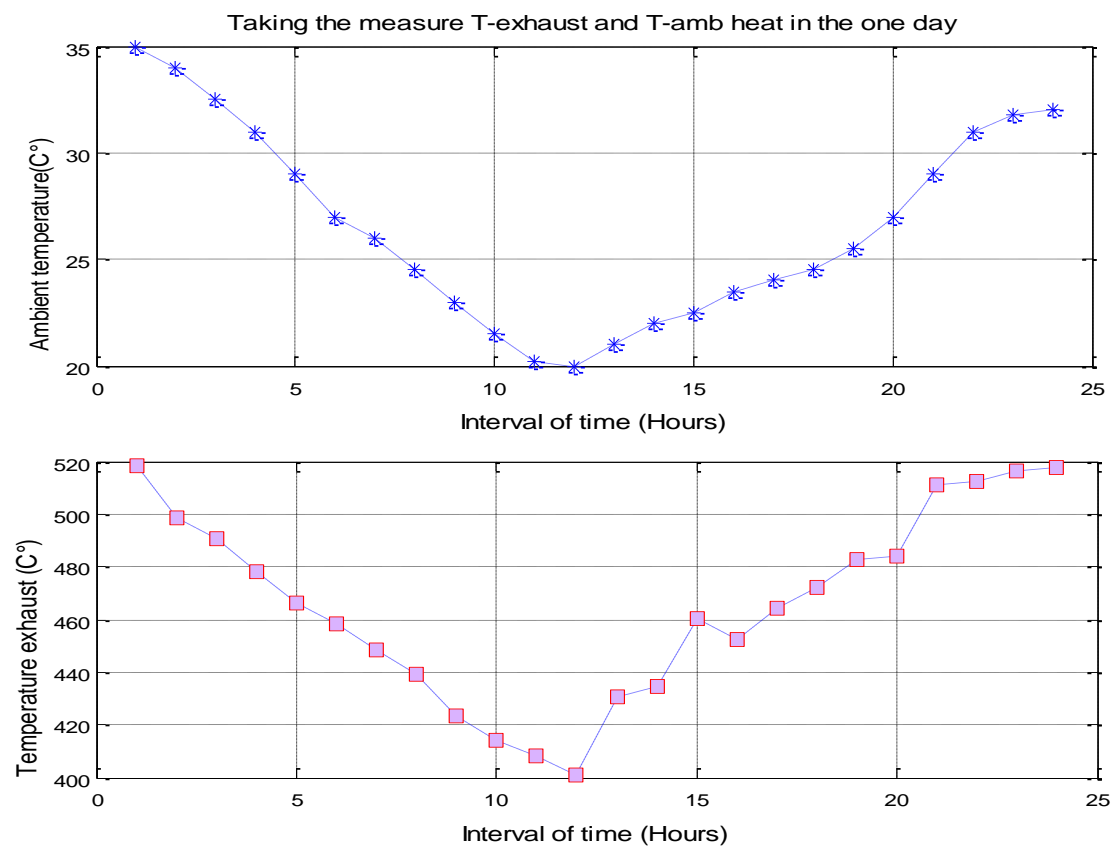

Fig. 6 Collected Data on the gas turbine parameters GE MS3002

The GDA (Default Gear Amplitude) that distinguishes irregularity "local" (default teeth or fin) and irregularity "global" due to a change in load or speed, for a 24 hours of observation of the studied turbine shown in Figure 7; thus to determine the source of vibration, which may be important to not endorse a mechanical degradation. But due to a malfunction, or problem 
guide assembly - equal to 0 of a gear "Perfect" - If the GDA tends to 1, the operation of the blade is disturbed by this anomaly, as it is shown in Figure 6.

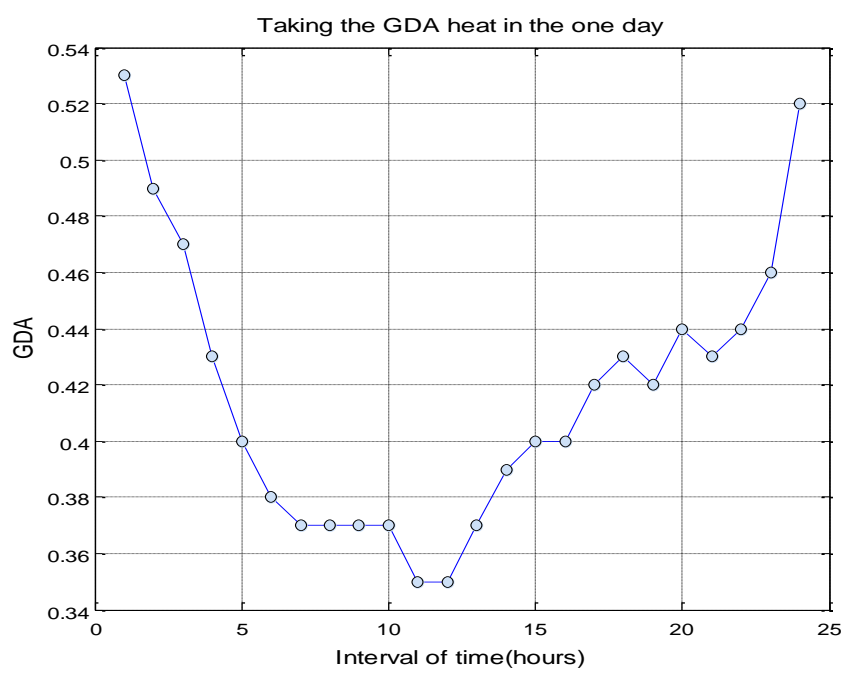

Fig. 7 Collected Data of Default Gear Amplitude

When the blade is heated asymmetrically either because excessively heated (high temperature) which causes a more intense heating of a side of the blade than the other. Furthermore, the deformation of dawn resulting from this heating in turn moves the hot spot (maximum vibration offset from the hot spot that gives it birth) then all the conditions are met to initiate a phenomenon of cyclic variations of the imbalance. Table 1 shows the different parameters of the studied turbine, for each variable, the various data are recorded.

Table 1: Different parameters of the examined GE MS 3002 turbine

\begin{tabular}{|c|c|c|c|c|c|c|c|c|c|c|c|c|}
\hline$T_{\text {echap }}\left(C^{\circ}\right)$ & 518. & 498. & 490. & 478. & 466. & 458. & 448. & 439. & 423. & 414. & 408. & 400 . \\
\hline$T_{a m b}\left(C^{0}\right)$ & 35 & 34 & 32.5 & 31 & 29 & 27 & 26 & 24.5 & 22.5 & 21.5 & 21.2 & 21.1 \\
\hline$R M S$ & 0.5 & 1.4 & 0.5 & 1.5 & 5.9 & 5.9 & 1.5 & 1.5 & 5.3 & 1.3 & 1.4 & 5.4 \\
\hline$F_{c}$ & 5.3 & 5.1 & 5.2 & 5.0 & 4.5 & 4.5 & 5.0 & 5.0 & 3.7 & 3.9 & 4.5 & 5.0 \\
\hline$V(\mathrm{~mm} / \mathrm{s})$ & 2.39 & 4.64 & 0.43 & 0.08 & 0.04 & 0.07 & 0.06 & 0.02 & 0.10 & 0.09 & 0.08 & 0.06 \\
\hline$G D A$ & 0.53 & 0.49 & 0.47 & 0.43 & 0.40 & 0.38 & 0.37 & 0.37 & 0.37 & 0.37 & 0.35 & \\
\hline$T_{\text {échap }}\left(C^{\circ}\right)$ & 430. & 434, & 460 & 452 , & 464 & 471 , & 482 , & 484 & 510 & 512. & 516. & \\
\hline$T_{a m b}\left(C^{0}\right)$ & 21 & 22 & 22,5 & 23,5 & 24 & 24,5 & 25,5 & 27 & 31 & 32 & 33 & 35 \\
\hline$R M S$ & 5.5 & 5.4 & 5.9 & 5.9 & 1.5 & 1.5 & 1.5 & 4.5 & 1.5 & 1.4 & 0.8 & 0.4 \\
\hline$F_{C}$ & 3.5 & 3.6 & 4.5 & 4.5 & 5.0 & 5.0 & 5.0 & 4.5 & 5.0 & 4.8 & 5.0 & 5 \\
\hline$V(\mathrm{~mm} / \mathrm{s})$ & 0.03 & 0.03 & 0.04 & 0.03 & 0.05 & 0.03 & 0.03 & 0.03 & 0.05 & 0.06 & 0.08 & 0.7 \\
\hline$G D A$ & 0.37 & 0.39 & 0.40 & 0.40 & 0.42 & 0.43 & 0.42 & 0.44 & 0.43 & 0.44 & 0.46 & \\
\hline
\end{tabular}

$\begin{array}{llllllllllll}E_{1} & E_{2} & E_{3} & E_{4} & E_{5} & E_{6} & E_{7} & E_{8} & E_{9} & E_{10} & E_{11} & E_{12}\end{array}$

In order to have the future state of the gas turbine system and to anticipate the appearance deficiencies caused by vibration in this system, other parameters are used such as the vibration speed and the crest factor. Figure 8 and 9 shows the variation of these parameters during $24 \mathrm{~h}$. 


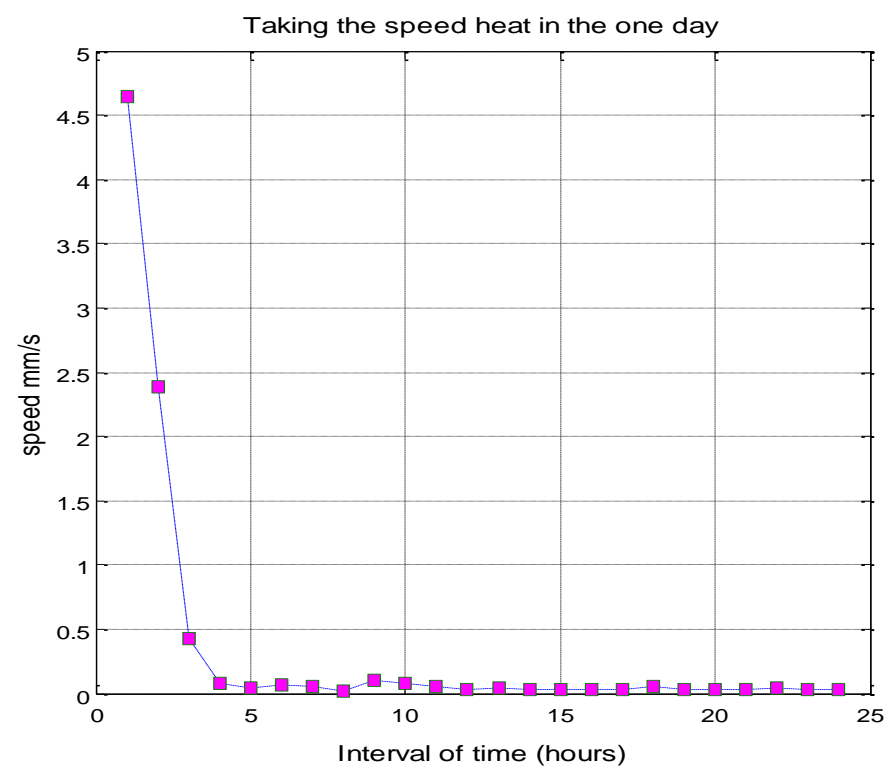

Fig. 8 Vibration speed variation

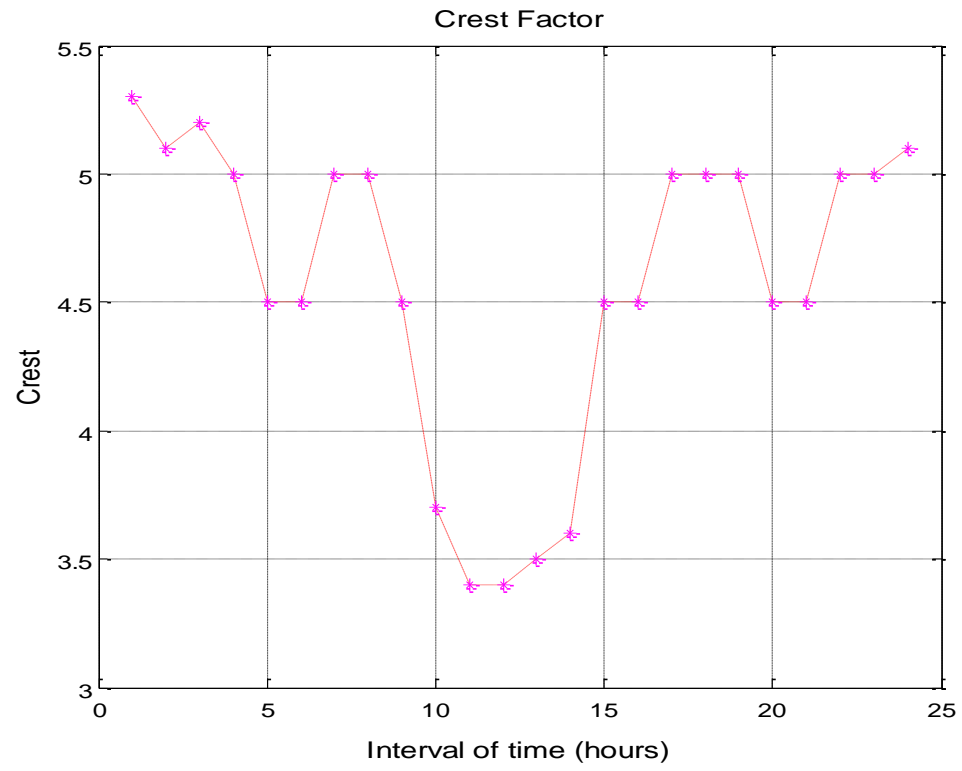

Fig. 9 Variation of peak factor

According to the statistical study on the industrial areas of the compressor station for the MS 3002 GE studied turbine, failures are detected due to vibrations of two bodies; The LT turbine that undergoes failure vibration with a time more than 330 hours, and the GG compressor which cause about $85 \%$ of total downtime with a time more than 214 hours. As a part of the proposed approach implementation, a statistical study of incomplete data in this work was done by calculations on the density estimations of incomplete data of the studied system. A Gaussian distribution is shown in Figure 10, which was used for the vibration in the fuzzy system prognosis based on the operating data of the gas turbine, however, the degradation is not measured but is can be identified by this approach. This Gaussian distribution, shown in Figure 10, was used to represent the vibrations in the fuzzy prognostic system, based on the operating data of the gas turbine, however the state of degradation is not measured but it is possible to identify it by this approach. At the time $t$, the degradation signal will have a Gaussian distribution function can be determined by: 


$$
y=f(x \mid \mu, \sigma) e \frac{-(x-\mu)^{2}}{2 \sigma^{2}}
$$

where $\mu$ is the mean and the second $\sigma$ is the standard deviation

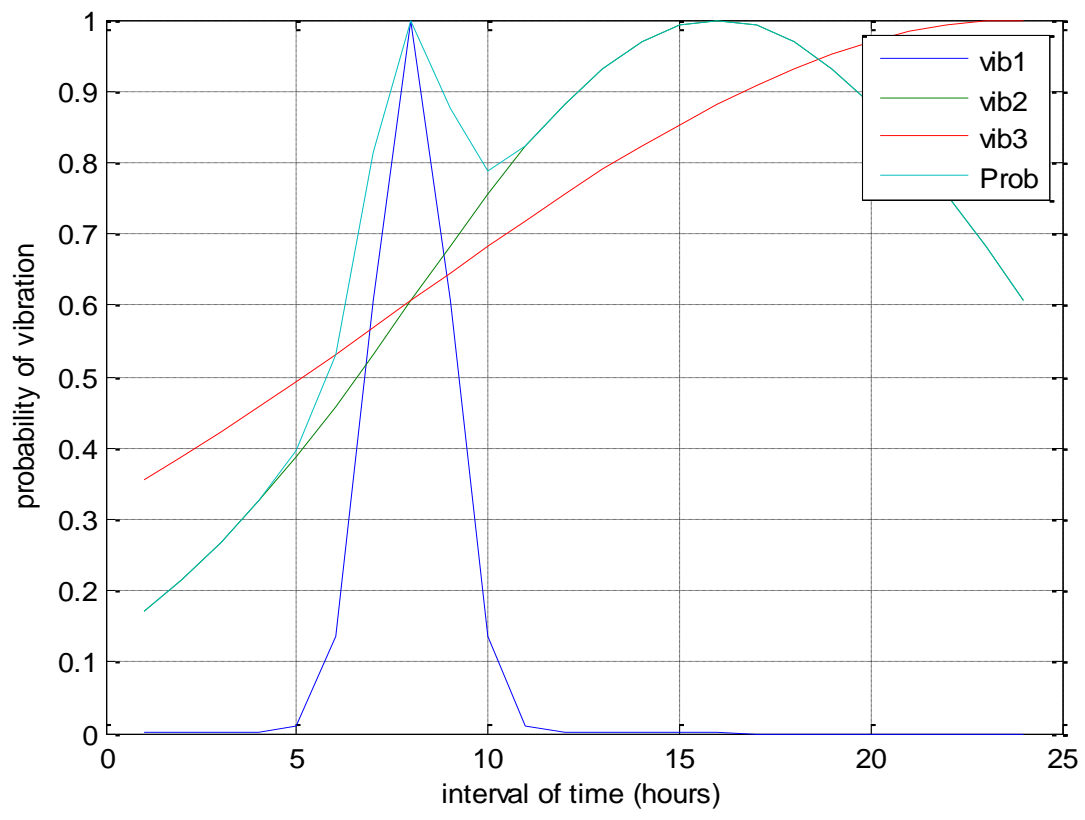

Fig. 10 Gaussian distribution of vibration signals

The prognosis by machine learning using fuzzy logic to predict the behavior of vibration to adjust the vibration detection thresholds so as to obtain the predicted output for each parameter of the turbine. Then is used to predict the evolution of degradation of these parameters under operational conditions of the turbine. To study the independence influence between the vibration settings obtained by the fuzzy prognostic approach guided by the studied turbine operating data with the combination of the two parameters crest factor variation and the vibration speed is set on the gas turbine system. Figure 11 shows the projection of the current state of a vibration component of the gas turbine on the prediction horizon of the proposed prognosis fuzzy system and the Figure 12 illustrates the prediction of vibration compared to the real vibration model.

The amplitudes of vibration system with the proposed fuzzy prognosis prediction were tested, as shown in Figure 13 and 14, these amplitudes are considered as the validation tests and the performance robustness of the proposed fuzzy prognosis method.

The proposed prognosis fuzzy approach was tested and validated with prediction errors that converge to zero more quickly when the horizon of observational data is small. Indeed, over the horizon of the data, the more accurate the prognosis is poor. This proposed prediction prognostic approach model allow the act of degradation of the components of the studied gas turbine and to predict the future state of vibration of the turbine components in given time horizons.

In the Figure 15, the first part of the prediction is presented with the interval of experimental time. We use a period of three months ( $\mathrm{T}=12$ weeks) with a step of 01 (one) week of each survey. Figure 16 shows the prediction of time interval vibrations over experimental periodicity, prediction made up to $(\mathrm{T}=16$ weeks $)$. 


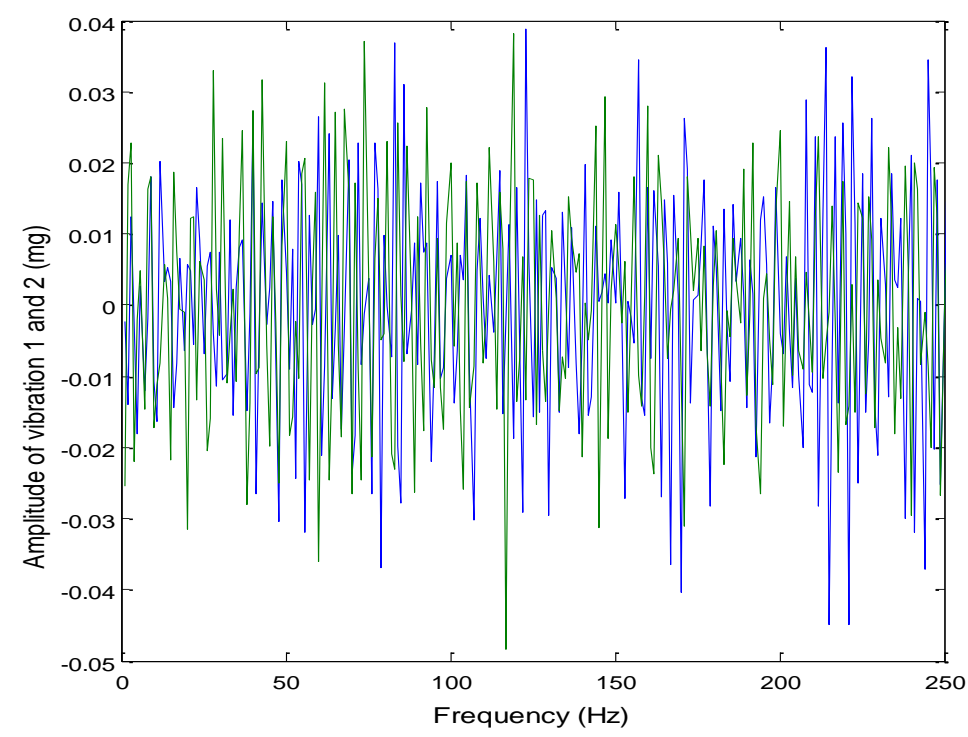

Fig. 11 Comparative vibrations extract

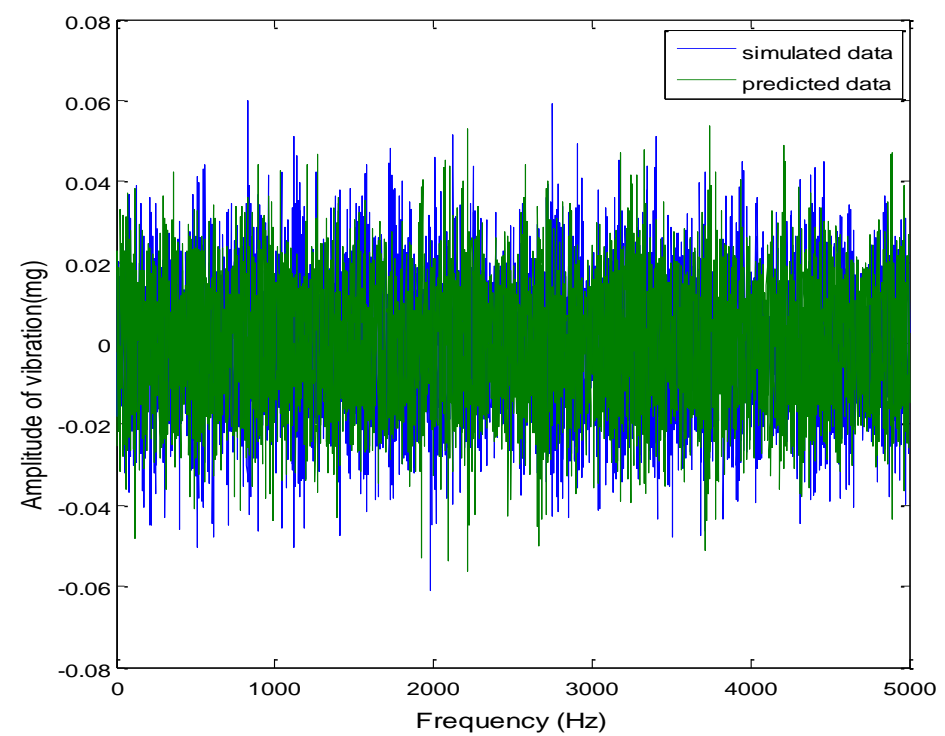

Fig. 12 Vibrations prediction

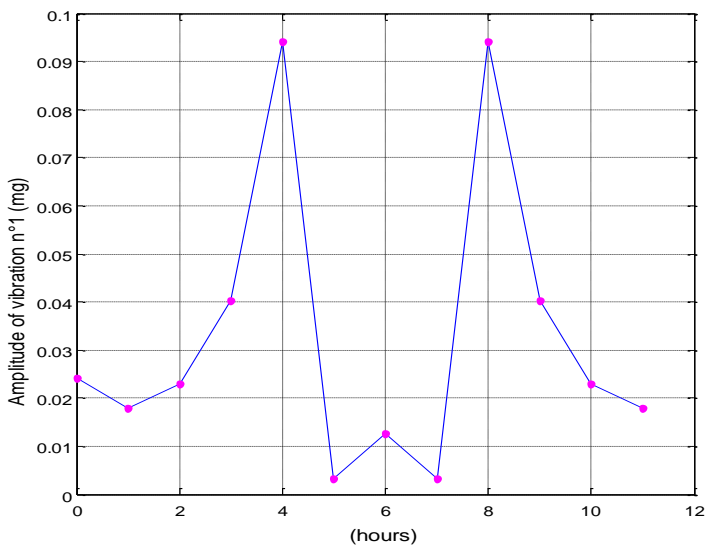

Fig. 13 Vibration amplitude Test 1

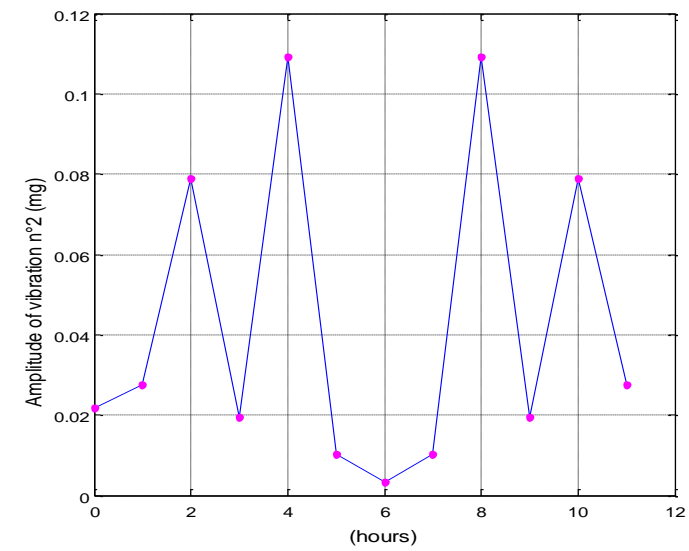

Fig. 14 Vibration amplitude Test 2 


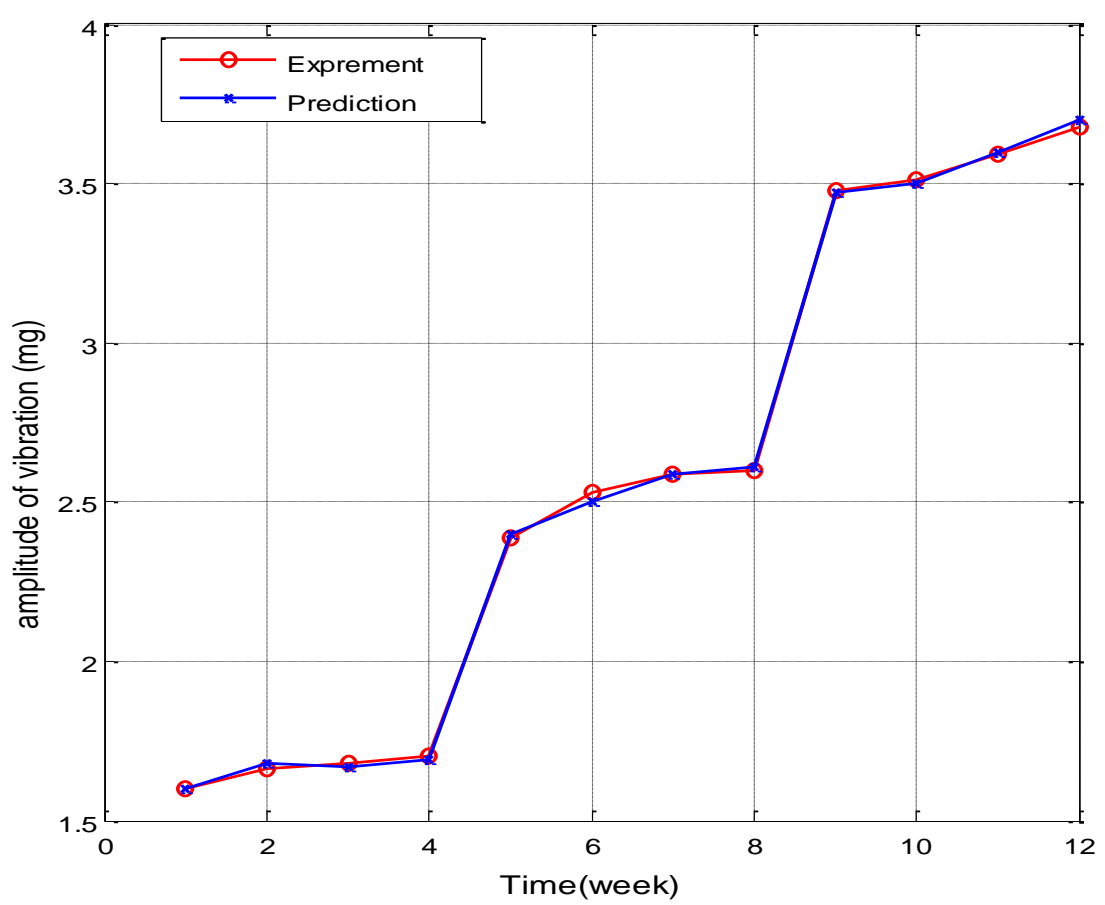

Fig. 15 Predicts the vibration trend of three months $(\mathrm{T}=12$ weeks)

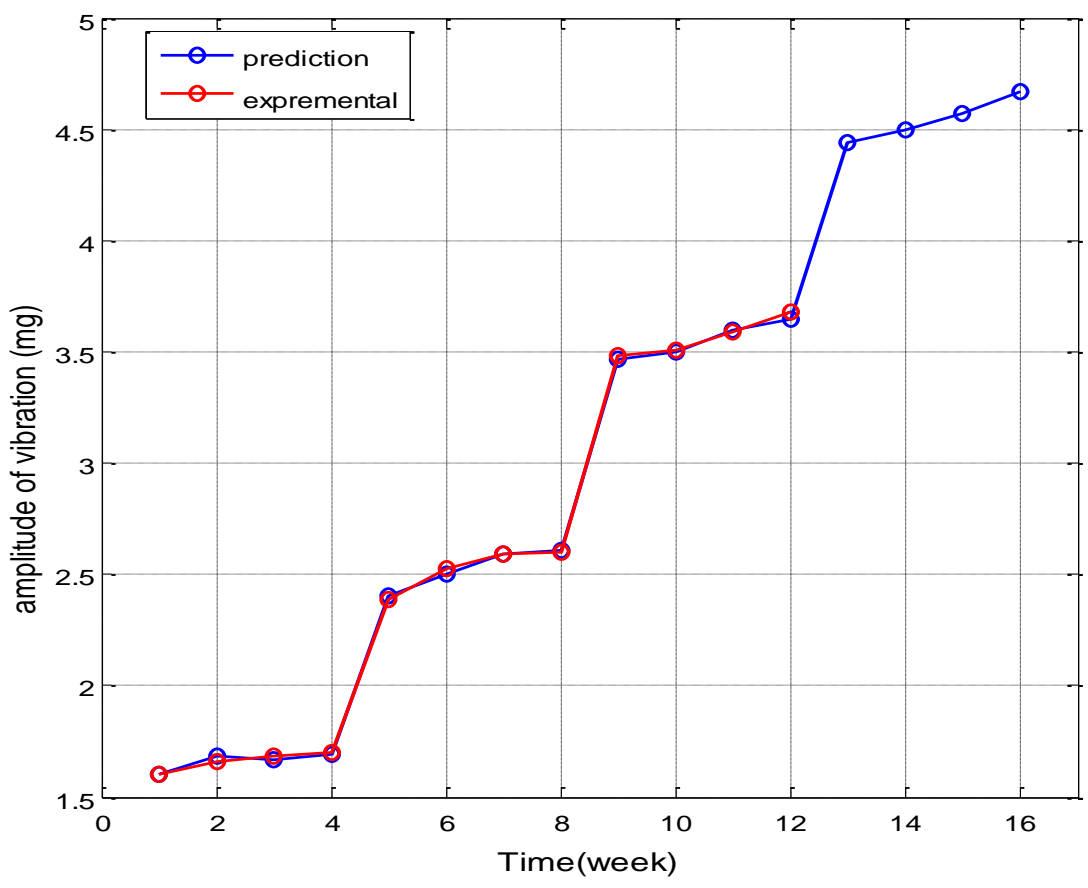

Fig. 16 Predicts the vibration trend at $(\mathrm{T}=16$ week $)$

Figure 17 illustrates the prediction of the time remaining before the gas turbine deterioration (residual life) starting from the twelfth week starting this week $(T=12$ week) . The hazard threshold (Amplitude $=4 \mathrm{mg}$ ) indicates the gas turbine incident point, in this case we find that the equivalent remaining lifetime ( $R U L=3$ week) of more than ( 21 days); Where the vibration at the bearings of the gas turbine at the end of this 20 s reach the alarm threshold (Amplitude $=4.61 \mathrm{mg}$ ), meaning that it is enough to perform all maintenance work. Here, we can say that our prognostic system has been well satisfied. 
We can see in Figure 18 that the prediction error does not exceed $03 \%$ and the most frequent prediction $\left(\frac{7}{12}\right)$ is the percentage of $01 \%$, that is to say for twelve weeks, which means that our prediction is clearly justified in a good meaning. In this step, we find the prediction error is checked by the following calculation:

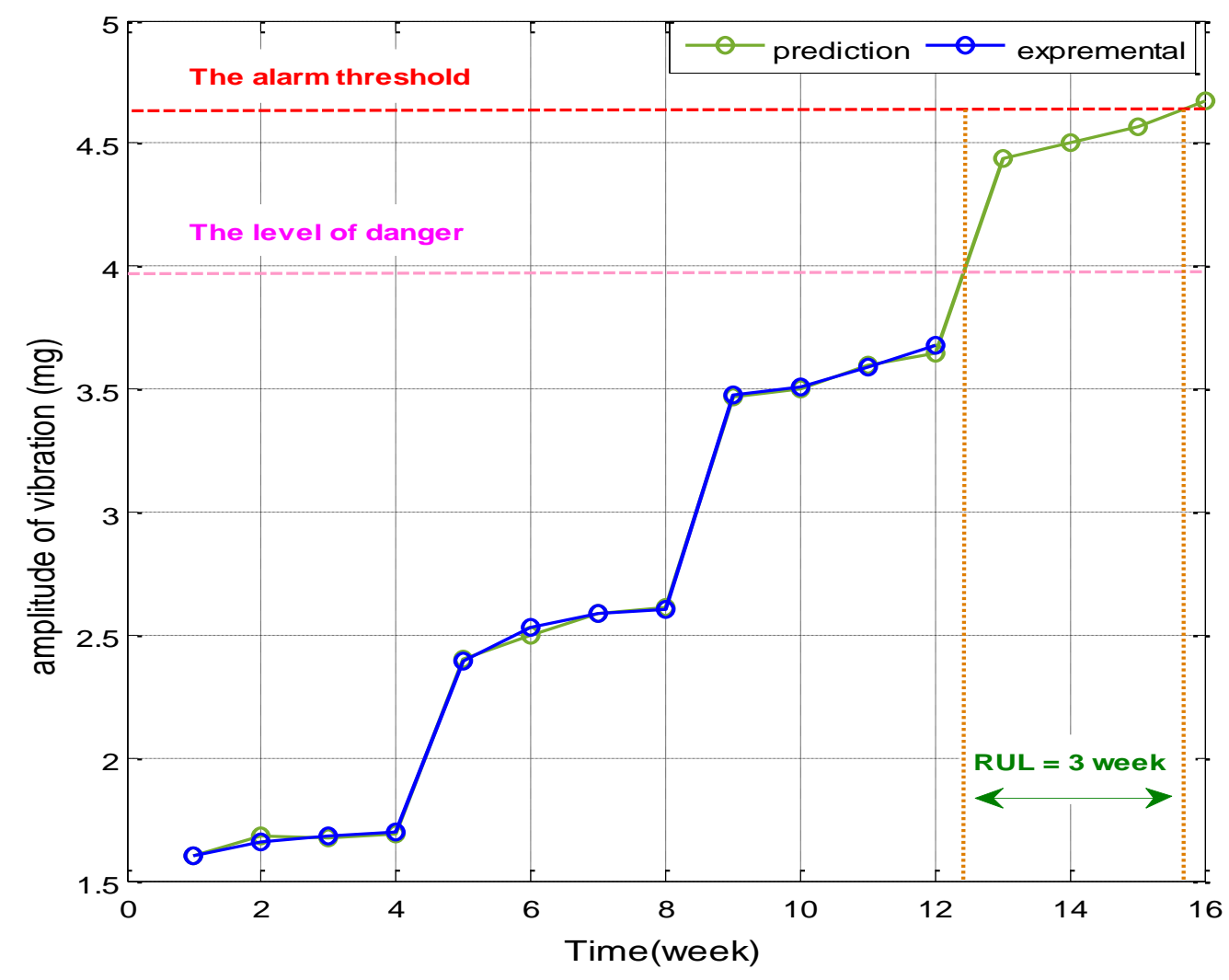

Fig. 17 Time remaining before the failure (RUL)

$$
\text { MAPE }=\frac{1}{12} \sum_{i=1}^{12} \frac{\mid \text { Actual }(i)-\text { Forecast }(i) \mid}{\text { Actual }(i)}=1.25 \%
$$

The $(1.25 \%)$ error is a reason for us to say that our prognostic system is one of the essential means to improve the maintenance strategy. 


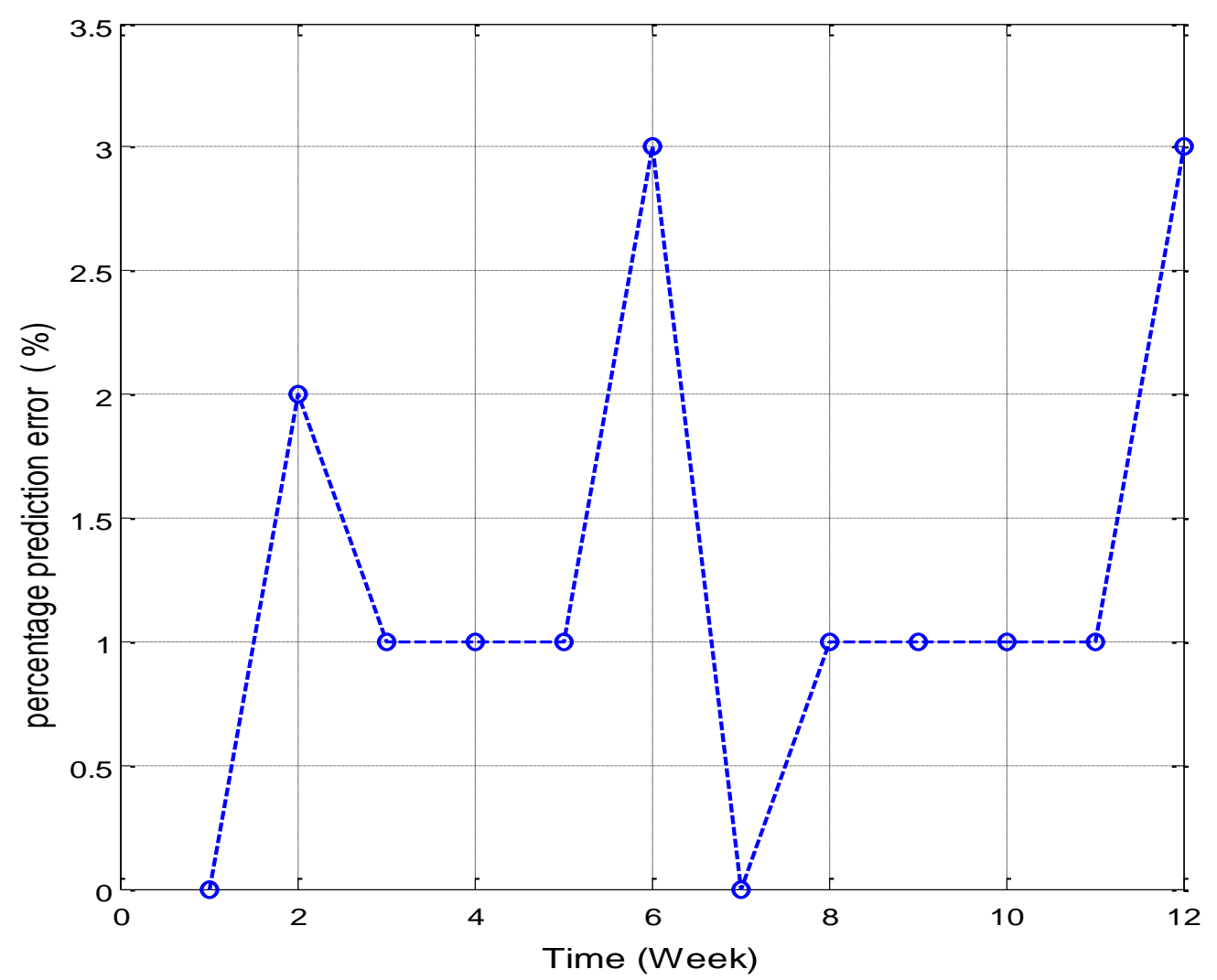

Fig. 18 Function of belonging of the various linguistic variables

\section{CONCLUSION}

The main aim of the proposed approach is to develop an efficient fuzzy prognosis system to achieve the supervision of the gas turbine vibrations and to ensure their continuous operation without any unexpected interruption. This proposed approach is based on the major benefit of the fuzzy logic which resides in its ability to translate a prognostic strategy of a skilled operator to a set of linguistic rules that can be interpreted easily. Whereas, the failure analysis of the studied turbine was carried out through the obtained data from the sensed vibrations signals representing the effective image of the studied systems failures. On the other side this analysis based on the proposed prognostic approach allows the prediction of the more probabilistic eventual damage of the studied systems before its final stop due to failures. Consequently, an implementation of such approach will ensure a predictive maintenance strategy of the considered systems based on real data obtained from vibration sensed signals to avoid their unexpected final stop. However, this proposed approach can be a promising solution for several rotating machines, especially in heavy industries applications where the interruption of the normal operation of such machine has a huge technical and economical impact on the industrial plants and that have to be avoided.

\section{REFERENCES}

[1] Jahromi, A. T., Er, M. J, Li, X., Lim, B. S. "Sequential fuzzy clustering based dynamic fuzzy neural network for fault diagnosis and prognosis", Neurocomputing 196, pp. 31 41, 2016.

[2] Djaidir, B., Hafaifa, A., Abdallah, K. "Faults detection in gas turbine rotor using vibration analysis under varying conditions" Journal of Theoretical and Applied Mechanics 55 (2), pp. 393 - 406, 2017. 
[3] Chen, B., Matthews, P. C., Tavner, P. J. "Wind turbine pitch faults prognosis using apriori knowledge-based ANFIS", Expert Systems with Applications 40 (17), pp. 6863 6876, 2013.

[4] Chen, B., Matthews, P. C., Tavner, P. J. "Wind turbine pitch faults prognosis using apriori knowledge-based ANFIS”, Expert Systems with Applications 40 (17), pp. 6863 6876, 2013.

[5] Fleischer, Ch., Waag, W., Bai, Z. "Dirk Uwe Sauer, On-line self-learning time forward voltage prognosis for lithium-ion batteries using adaptive neuro-fuzzy inference system”, Journal of Power Sources 243, pp. 728 - 749, 2013.

[6] Kwon, D., Yoon, J. “A model-based prognostic approach to predict interconnect failure using impedance analysis", Journal of Mechanical Science and Technology 30 (10), pp. 4447 - 4452, 2016.

[7] Li, D., Wang, W., Ismail, F. "Enhanced fuzzy-filtered neural networks for material fatigue prognosis", Applied Soft Computing 13 (1), pp. 283 - 291, 2013.

[8] Ewins D. J. "Control of vibration and resonance in aero engines and rotating machinery - An overview", International Journal of Pressure Vessels and Piping 87 (09), pp. 504 $510,2010$.

[9] Sica, F. C., Guimarães, F. G., Duarte, R. O., Agnaldo, J. R. R. “A cognitive system for fault prognosis in power transformers", Electric Power Systems Research 127, pp. 109 $117,2015$.

[10] Tsai, G. Ch. "Rotating vibration behavior of the turbine blades with different groups of blades", Journal of Sound and Vibration 271 (3-5, 6), pp. 547 - 575, 2004.

[11] Hafaifa, A., Mouloud, G., Daoudi, A. "Vibration supervision in gas turbine based on parity space approach to increasing efficiency", Journal of Vibration and Control 21, pp. $1622-1632,2015$.

[12] Kanoglu, M., Dincer, I., Rosen, M. A. "Understanding energy and exergy efficiencies for improved energy management in power plants", Energy Policy 35 (1), pp. 3967 3978, 2007.

[13] Kessentini, S., Choura, S., Najar, F., Franchek, M. A. "Modeling and dynamics of a horizontal axis wind turbine", Journal of Vibration and Control 16 (13), pp. 2001 2021, 2010.

[14] Žmindák, M. "Dynamic and sensitivity analysis general non-conservative asymmetric mechanical systems", Strojnícky časopis - Journal of Mechanical Engineering 68 (2), pp. 105 - 124, 2018. DOI: $10.2478 /$ scjme-2018-0021

[15] Benrahmoune, M., Hafaifa, A., Mouloud, G. "Vibration modeling improves pipeline performance, costs", Oil \& Gas Journal 113 (03), pp. 98 - 100, 2015.

[16] Benrahmoune M., Hafaifa, A., Guemana, M., Chen, X. "Detection and modeling vibrational behavior of a gas turbine based on dynamic neural networks approach", Strojnícky časopis - Journal of Mechanical Engineering 68 (3), pp. 143 - 166, 2018. DOI: $10.2478 /$ scjme-2018-0032

[17] Hadroug, N., Hafaifa, A., Kouzou, A. "Mouloud Guemana and Ahmed Chaibet, Control of the speed and exhaust gas temperature in gas turbine using adaptive neuro-fuzzy inference system", Journal of Automation \& Systems Engineering, 10 (3), pp. 158 167, 2016. 
[18] Nadji, H., Ahmed, H., Bachir, A., Abdelhamid, I., Chen, X. "Fuzzy diagnostic strategy implementation for gas turbine vibrations faults detection: Towards a characterization of symptom-fault correlations", Journal of Vibration Engineering \& Technologies, 2021. DOI: $10.1007 / \mathrm{s} 42417-021-00373-\mathrm{z}$

[19] Nadji, H., Ahmed, H., Kouzou, A., Ahmed, Ch. "Dynamic model linearization of two shafts gas turbine via their input / output data around the equilibrium points", Energy Elsevier 120, pp. 488 - 497, 2017.

[20] Okipnyi, I., Poberezhny, L., Zapukhliak, V., Hrytsanchuk, A, Poberezhna, L., Stanetsky, A., Kravchenko, V., Rybitskyi, I. "Impact of long-term operation on the reliability and durability of transit gas pipelines", Strojnícky časopis - Journal of Mechanical Engineering 70 (1), pp. 115 - 126, 2020. DOI: 10.2478/scjme-2020-0011

[21] Qinming, L., Ming, D., Wenyuan, L., Xiuli, G., Yupeng, L. "A novel method using adaptive hidden semi-Markov model for multi-sensor monitoring equipment health prognosis”, Mechanical Systems and Signal Processing 64-65, pp. 217 - 232, 2015.

[22] Stetter, R., Witczak, P., Spindler, C., Hertel, J., Witczak, M. "Intelligent Systems for the Prognosis of Energy Consumption in Manufacturing and Assembly", Procedia CIRP 33, pp. 370 - 375, 2015.

[23] Owsiński, R., Niesłony, A. "Identification of fatigue cracks on the basis of measurable changes in system dynamics", Strojnícky časopis - Journal of Mechanical Engineering 67 (2), pp. 77 - 84, 2017. DOI: 10.1515/scjme-2017-0020

[24] Smoczek J., Szpytko, J. "Evolutionary algorithm-based design of a fuzzy TBF predictive model and TSK fuzzy anti-sway crane control system", Engineering Applications of Artificial Intelligence 28, pp. 190 - 200, 2014.

[25] Hua, S., Yi, Z., Maolin, Z., Jingjing, S. "Fault prognosis approach for satellite attitude control system based on T-S Model and time series analysis", IFAC Proceedings 46 (20), pp. $456-461,2013$.

[26] Welte, T. M., Wang, K. "Models for lifetime estimation: an overview with focus on applications to wind turbines", Advances in Manufacturing 2 (1), pp. 79 - 87, 2014.

[27] Traore M., Chammas, A., Duviella, E. "Supervision and prognosis architecture based on dynamical classification method for the predictive maintenance of dynamical evolving systems", Reliability Engineering \& System Safety 136, pp. 120 - 131, 2015.

[28] Tůma, J., Šuránek, P.], Žiaran, S. "All-Pass filters in the systems of active vibration control of weakly-damped systems", Strojnícky časopis - Journal of Mechanical Engineering 68 (4), pp. 65 - 74, 2018. DOI: 10.2478/scjme-2018-0048

[29] Leturiondo, U., Salgado, O., Ciani, L., Galar, D., Catelani, M. “Architecture for hybrid modelling and its application to diagnosis and prognosis with missing data", Measurement 108, pp. 152 - 162, 2017.

[30] Tran, V. T., Yang, B-S., Tan, A. Ch. Ch. "Multi-step ahead direct prediction for the machine condition prognosis using regression trees and neuro-fuzzy systems", Expert Systems with Applications 36 (5), pp. 9378 - 9387, 2009.

[31] Wang, W. Q., Golnaraghi, M. F., Fathy, I., "Prognosis of machine health condition using neuro-fuzzy systems", Mechanical Systems and Signal Processing 18 (4), pp. 813 $-831,2004$. 
[32] Chen, X., Yu, J., Tang, D., Wang, Y. “A Novel PF-LSSVR-based framework for failure prognosis of nonlinear systems with time-varying parameters", Chinese Journal of Aeronautics 25 (5), pp. 715 - 724, 2012.

[33] Tian, X., Cao, Y. P., Chen, S. "Process fault prognosis using a fuzzy-adaptive unscented Kalman predictor", International Journal of Adaptive Control and Signal Processing, , 25 (9), pp. 813 - 830, 2011.

[34] Lei, Y., He, Z., Zi, Y., Hu, Q. "Fault diagnosis of rotating machinery based on a new hybrid clustering algorithm", The International Journal of Advanced Manufacturing Technology 35 (9-10), pp. 968 - 977, 2008.

[35] Pan, Y., Er, M. J., Li, X., Yu, H., Gouriveau, H. "Machine health condition prediction via online dynamic fuzzy neural networks", Engineering Applications of Artificial Intelligence 35, pp. 105 - 113, 2014.

[36] Wu, X., Hong G. S., Wong W.S. "Prognosis of the probability of failure in tool condition monitoring application-a time series based approach", The International Journal of Advanced Manufacturing Technology 76 (1-4), pp. 513 - 521, 2015. 